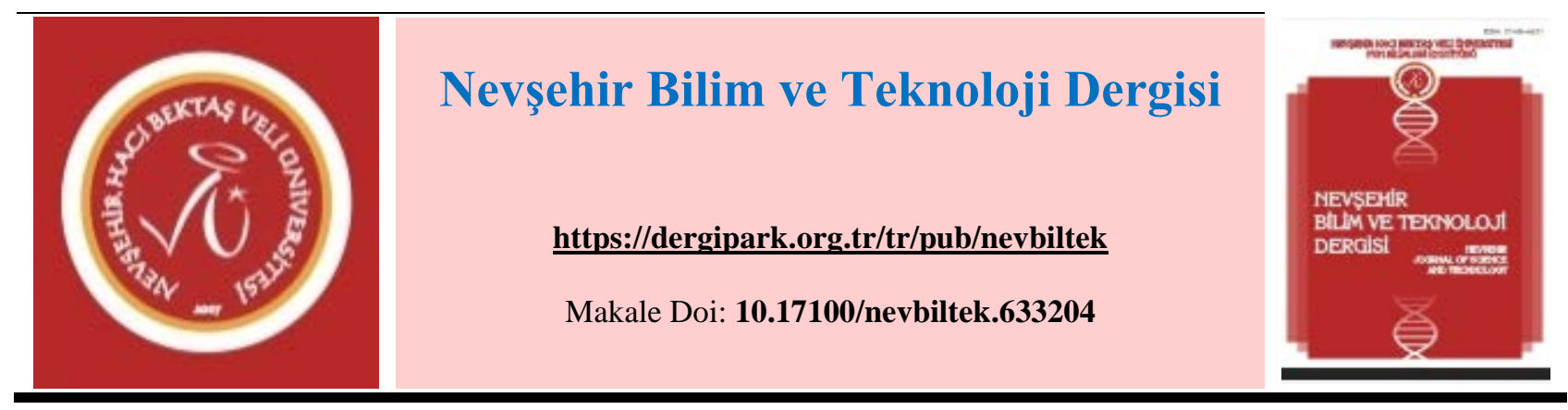

\title{
17-4 PH Paslanmaz Çeliklerin Tornalamasında Farklı Kaplama Tiplerinin Kesme Kuvvetlerine Etkilerinin İncelenmesi
}

\author{
Saltuk Alper YAŞAR ${ }^{1,}$, Gültekin UZUN ${ }^{2}$, İhsan KORKUT ${ }^{3}$ \\ ${ }^{1}$ Gazi Üniversitesi, Teknoloji Fakültesi, Imalat Mühendisliği Bölümü, Ankara \\ ORCID ID: 0000-0002-1050-5403 \\ ${ }^{2}$ Gazi Üniversitesi, Teknoloji Fakültesi, İmalat Mühendisliği Bölümü, Ankara \\ ORCID ID: 0000-0002-6820-8209 \\ ${ }^{3}$ Gazi Üniversitesi, Teknoloji Fakültesi, Imalat Mühendisliği Bölümü, Ankara \\ ORCID ID: 0000-0002-5001-4449
}

Öz

Çökelme sertleşmesi ile yaşlandırılmış paslanmaz çelikler, diğer paslanmaz çelik türlerine göre daha üstün özelliklere sahiptir. Bu üstün özeliklerin en önemlileri mekanik ve termal özelliklerdir. 17-4 PH paslanmaz çeliği; nükleer endüstriden havacılık endüstrisine kadar birçok alanda tercih edilmektedir. Bu çalışmada, 17-4 PH paslanmaz çeliğinin farklı kaplama türlerine sahip kesici takımlar ile işlenmesi sırasında, işleme parametrelerinin esas kesme ve ilerleme kuvvetlerine olan etkileri incelenmiştir. İşlenebilirlik çalışmaları, CNC torna tezgahında gerçekleştirilmiş olup, dörder farklı kesme hızı, ilerleme oranı ve kesme derinliği işleme parametreleri olarak belirlenmiştir. Kesici takım olarak aynı geometriye sahip, PVD ve CVD kaplamalı takımlar kullanılmıştır. Deneylerin uygulanması için seçilmiş değişkenlere Taguchi $\mathrm{L}_{16}$ ortogonal dizini uygulanarak deney sayısı en aza indirgenmiştir. Elde edilen sonuçların etkili bir biçimde yorumlanması, esas kesme ve ilerleme kuvvetleri açısından en etkin parametrelerin belirlenmesi için varyans analizi (ANOVA) uygulanmıştır. Yapılan deneysel çalışmaların sonucunda 17-4 PH paslanmaz çelikleri için esas kesme ve ilerleme kuvvetleri açısından optimum kesme parametrelerinin tayini gerçekleştirilmiştir. Sonuç olarak, her iki kaplama türünde ilerleme oranı ve kesme derinliği esas kesme ve ilerleme kuvveti değerlerinde artışa neden olmuştur. Kesme hızının artışı ile her iki kaplama türünde de esas kesme kuvveti değerlerinde \%8,05 ile \%25,24 arasında azalma görülmüştür. Ancak PVD kaplamalı takımlarda artan kesme hızı ile ilerleme kuvveti değerlerinde $\% 0,97$ ile $\% 3,18$ arasında azalma, CVD kaplamalı takımlarda ise $\% 2,78$ ile $\% 7,11$ arasında artış olduğu belirlenmiştir.

Anahtar Kelimeler: 17-4 PH, Paslanmaz çelik, Kesme kuvveti, ANOVA, İşlenebilirlik

\section{Investigation of the Effects of Different Coating Types on Cutting Forces in Turning of 17-4 PH Stainless Steels}

Abstract

Precipitation hardened stainless steels have more superior properties than other stainless steel types. The most important ones of these superior properties are its mechanical and thermal properties. From nuclear industry to aviation industry, 17-4 PH stainless steels are favored in many industries. In this study, during machining of 17-4 PH stainless steel with different coated cutting tools, the effect of cutting parameters on main cutting force and feed force was investigated. Machinability studies were executed on CNC turning machine. Four different cutting speeds, four different feed rates and four different cutting depths were determined as cutting parameters. Geometrically identical PVD and CVD coated cutting tools were used. In order to perform the study, Taguchi $\mathrm{L}_{16}$ orthogonal array were applied to the selected variables for optimizing the number of experiments. Analysis of variance (ANOVA) was applied on behalf of commenting the obtained results influentially and for determining the most effective parameters in terms of main cutting forces and feed forces. As a result of the experimental studies, optimum cutting parameters were determined with regards to main cutting force and feed force. Increasing feed rate and cutting depth increase main cutting force and feed force values during machining with both coating types. Moreover, increasing cutting speed reduces main cutting force values between $8,05 \%$ and $25,24 \%$ during machining with both coating types. However, it was determined that increasing cutting force decreases the feed force values between $0,97 \%$ and 3,18\% machining with PVD cutting tools, increases feed force values between 2,78\% and 7,11\% machining with CVD cutting tools, consequently.

Keywords: 17-4 PH, Stainless steel, Cutting forces, ANOVA, Machinability 


\section{Giriş}

Malzemelerin şekillendirilmesi, nihai ürünün elde edilmesi için talaşlı imalat günümüzün vazgeçilmez imalat yöntemlerinden biridir; bu yöntemlerden birisi de tornalama operasyonudur [1]. Bu operasyonun gerçekleştirilmesinde çeşitli kriterlerin değerlendirilmesi gerekmektedir, bunlardan birisi de işlenebilirliktir. İşlenebilirlik sadece malzeme özelliklerine bağlı olmayıp, işleme yöntemi ve parametrelerine de bağlı olduğu literatürde belirtilmiştir. Kesme kuvvetlerinin incelenmesi, işlenebilirliğin değerlendirilmesi için bilinen bir yöntemdir [2 ve 3].

Günümüz şekillendirme operasyonlarının büyük bir çoğunluğu kaplamalı kesici takımlar ile yapılmaktadır. Kesici takım kaplamasında temel anlamda fiziksel buhar biriktirme (PVD) ve kimyasal buhar biriktirme (CVD) yöntemleri kullanılmaktadır. Kesici takım kaplamasının dayanıklı olabilmesi için iyi derecede takım malzemesine tutunma kabiliyetine, aşınma dayanımına, aşınma direncine, kimyasal kararlılığa ve yorulma tokluğuna sahip olması beklenmektedir. PVD ve CVD kaplamalar bu ihtiyaçları karşılayabilmektedir. İşlenebilirliği zor olan malzemeler üzerinde yapılan çalışmalarda PVD ve CVD kaplamalı takımların kullanılması oldukça yaygın olarak rastlanan bir durumdur [4-6].

Paslanmaz çelikler son zamanlarda kullanılan mühendislik malzemelerinin başında gelmektedir. Mekanik ve termal özelliklerin artışının tespiti ile bu malzemelerin kullanım alanları özelleşmiştir [7]. Çökelme sertleştirilmesi ile yaşlandırılmış paslanmaz çelikler yüksek korozyon dayanımı, yüksek dayanıma ve sertliğe sahip olması nedeniyle sanayide oldukça fazla kullanım alanına sahiptir [8]. Çökelme sertleştirilmesi ile yaşlandırılmış paslanmaz çeliklerden martenzitik türü birçok alanda kullanım yerine sahiptir. Martenzitik paslanmaz çelik sınıfina ait olan 17-4 PH paslanmaz çeliği ise bu tür içinde dikkat çeken bir malzemedir. Petrol, gaz ve havacılık endüstrilerinde sıklıkla kullanımına yer verilmektedir [9 ve 10$]$.

Aynı alanlarda kullanıma müsait titanyum alaşımlarına nazaran bu malzemenin kullanımına yer verilmesi, maliyeti azaltıcı yönde etki etmektedir. Ancak bu malzemenin yüksek sünekliğe, düşük 1sıl iletkenliğe sahip olması, pekleşme, yığıntı talaş (Built up edge-BUE), uzun ve yapışık talaş oluşturma eğilimi sebebiyle işlenebilirliği problemli olan bir malzeme olarak tanımlanmıştır [11 ve 12].

Genel olarak literatür incelendiğinde, PVD ve CVD kaplamalı takımlar ile işleme esnasında kesme hızının artışı ile kesme kuvvetlerinde azalma olduğu belirtilmiştir [13-15]. İşleme verimliğinin artırılması için kesme hızının artışının önemi araştırmacılar tarafından vurgulanmıştır. Ancak belirli bir değerin üzerindeki kesme hızları takım aşınması meydana getireceğinden ötürü kesme kuvvetlerinde artışa sebep olacağı belirtilmiştir [15 ve 16]. Her iki kaplama türünde de ilerleme oranının ve kesme derinliğinin artırılmasıyla kesme kuvvetlerinin arttığı vurgulanmıştır [14-17]. Yapılan çalışmalar incelendiğinde, genel olarak CVD kaplamalı takımların bu malzemelerin işlenmesinde kullanıldığı görülmektedir. Ancak yeni teknolojiler ile PVD kaplamalı takımların da paslanmaz çeliklerin işlenmesinde kullanılabileceği literatür tarafından belirtilmiştir [18].

Bu çalışmada, 17-4 PH paslanmaz çeliğinin tornalanmasında oluşan esas kesme ve ilerleme kuvvetlerine aynı geometriye sahip PVD ve CVD kaplamalı takımların ve farklı kesme parametrelerinin etkilerinin Taguchi metodu kullanılarak araştırılması ve optimum kesme parametrelerinin belirlenmesi amaçlanmıştır.

\section{Materyal ve Metot}

\subsection{Takım Tezgahı}

Gazi Üniversitesi İmalat Mühendisliği Laboratuvarları bünyesinde bulunan, Johnford marka TC-35 model $\mathrm{CNC}$ torna tezgahında deneyler gerçekleştirilmiştir.

\subsection{Kesme Kuvvetlerinin Ölçümü}

Deneyler sırasında oluşan kesme kuvvetlerinin ölçümü amacıyla Kistler marka 9257B model piezoelektrik dinamometre kullanılmıştır. Dinamometre aynı markanın Type 5019 model sinyal yükselticisine (Multichannel Charge Amplifier) bağlanmış olup, sinyal yükselticisinden bilgisayara veri aktarımı RS-232C ara kablo ile sağlanmıştır. İletilen veriler Dynoware programının Type 2825Ai-2 versiyonu ile kesme kuvvetlerinin operasyon esnasındaki değişimleri grafik haline getirilmiştir. Deney seti Şekil 1'de gösterilmiştir. 


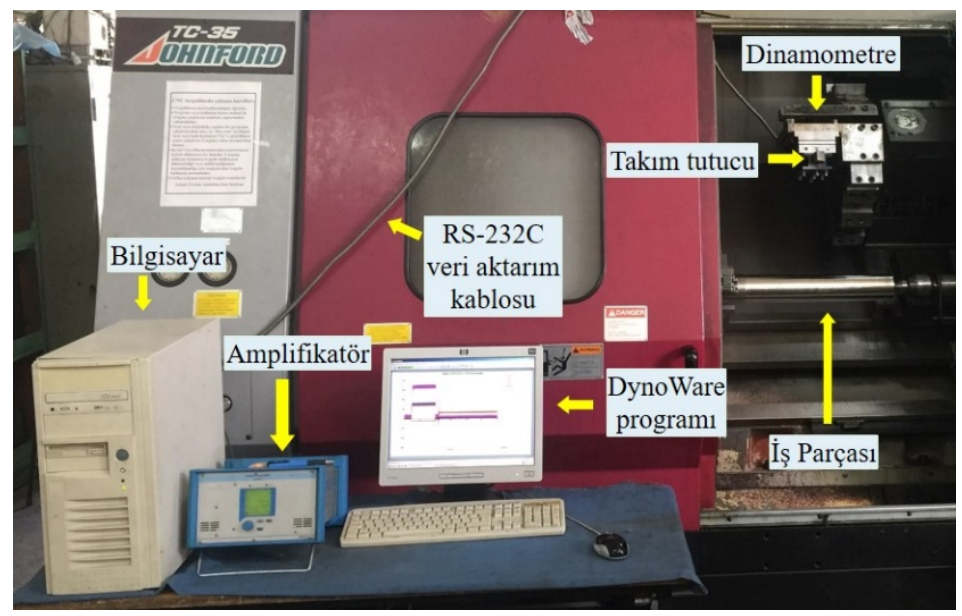

Şekil 1. Deney seti

\subsection{Deney Numuneleri}

Deney numunesi olarak 17-4 PH paslanmaz çeliği kullanılmıştır. Deney numunesinin çapı 80 mm, boyu 500 mm'dir. Spekturum analiz raporunda belirtildiği üzere 37 HRC sertliğe sahip olan numune, H1025 1sıl işlemine tabi tutulmuş olarak temin edilmiştir. Tablo 1'de malzemenin üretici firma tarafindan belirtilen kimyasal kompozisyon belirtilmiştir.

Tablo 1. Malzemenin kimyasal kompozisyonu (Ağırlı \%)
\begin{tabular}{|c|c|c|c|c|c|}
\hline $\mathbf{C}$ & $\mathbf{S i}$ & $\mathbf{M n}$ & $\mathbf{N i}$ & $\mathbf{C r}$ & $\mathbf{M o}$ \\
\hline 0,018 & 0,318 & 0,818 & 4,517 & 15,311 & 0,142 \\
\hline $\mathbf{C u}$ & $\mathbf{S}$ & $\mathbf{P}$ & $\mathbf{N b}$ & $\mathbf{C o}$ & $\mathbf{T a}$ \\
\hline 3,082 & 0,0202 & 0,0241 & 0,196 & 0,063 & 0,01 \\
\hline
\end{tabular}

\subsection{Kesici Takım}

Deneylerde Sandvik Coromant firmasının aynı geometriye sahip PVD ve CVD kaplamalı takımları kullanılmıştır. Bu takımların kodu SNMG 120408-MM olarak üretici firma tarafından isimlendirilmiştir. Kesici takımların kaplamaları Şekil 2'de gösterilmiştir.

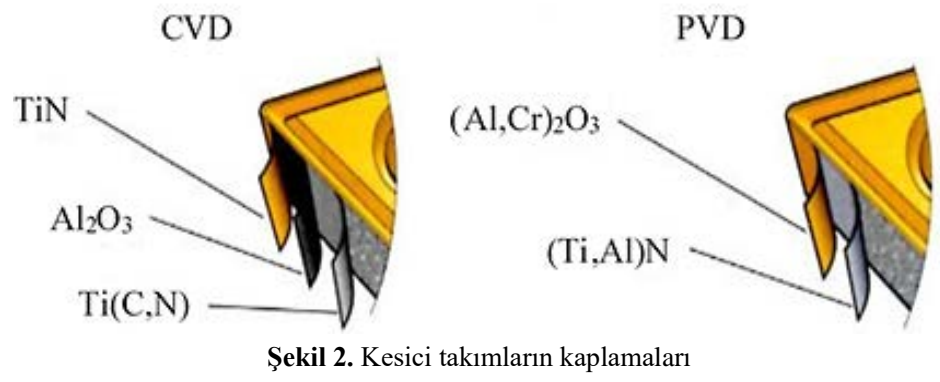

\subsection{Kesme Parametreleri}

Deneylerde TS ISO 3685 standardı, kesici takım firmasının önerdiği değerler ve literatür göz önünde bulundurularak; dörder farklı kesme hızı (150,168,210 ve $240 \mathrm{~m} /$ dak), ilerleme oranı $(0,125,0,16,0,2 \mathrm{ve} 0,25 \mathrm{~mm} / \mathrm{dev})$ ve kesme derinliği $(1,1,25,1,6$ ve $2 \mathrm{~mm})$ kesme parametreleri olarak belirlenmiştir. Taguchi $\mathrm{L}_{16}$ deney tasarımından yararlanılan çalışmada, kesme parametrelerinin kontrol faktör ve seviyeleri Tablo 2’de verilmiştir.

Tablo 2. Kontrol faktörü ve seviyeleri

\begin{tabular}{|c|c|c|c|c|c|}
\hline Kontrol Faktörleri & Sembol & Seviye 1 & Seviye 2 & Seviye 3 & Seviye 4 \\
\hline Kesme Hızı (m/dak) & V & 150 & 168 & 210 & 240 \\
\hline İlerleme Oranı (mm/dev) & F & 0,125 & 0,16 & 0,2 & 0,25 \\
\hline Kesme Derinliği (mm) & A & 1 & 1,25 & 1,6 & 2 \\
\hline
\end{tabular}




\section{Bulgular}

Deneyler Taguchi L16 ortogonal dizini yardımıyla hem PVD hem de CVD kaplamalı takımlar için gerçekleştirilmiştir.

\subsection{Esas Kesme Kuvvetlerinin Değerlendirilmesi}

Şekil 3 ve Şekil 4 incelendiğinde, PVD ve CVD kaplamalı takımlar için esas kesme kuvveti açısından en etkin parametrenin kesme derinliği, onu takiben ilerleme oranı olduğu belirlenmiştir. PVD ve CVD kaplamalı takımlar için yapılan varyans analizleri sonucunda elde edilen bu grafiklerin ışı̆̆ında, esas kesme kuvveti için regresyon denklemleri oluşturulmuştur (Denklem 3.1 ve Denklem 3.2).

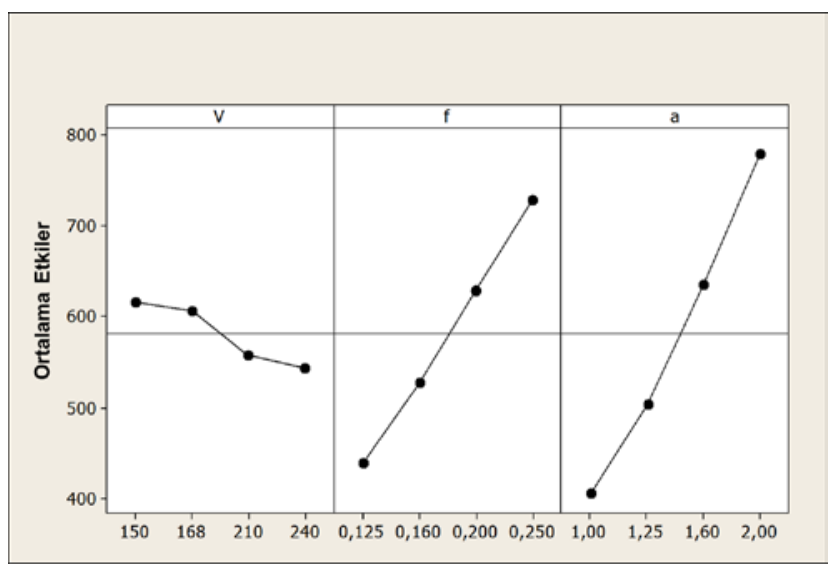

Şekil 3. PVD kaplamalı takımlar için esas kesme kuvveti açısından ortalama etkiler

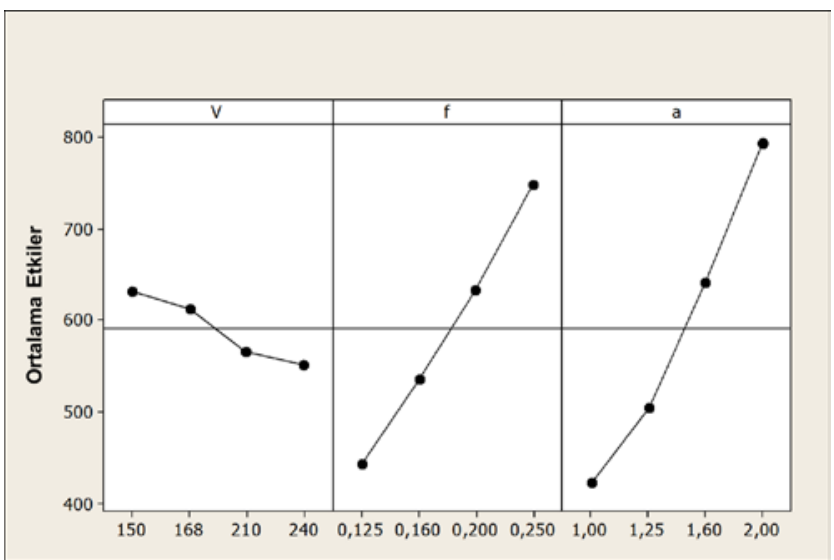

Şekil 4. CVD kaplamalı takımlar için esas kesme kuvveti açısından ortalama etkiler

$$
\begin{aligned}
& \mathrm{F}_{\mathrm{CPVD}}=-221,33-0,869949 \times \mathrm{V}+2319,12 \times \mathrm{f}+372,099 \times \mathrm{a} \\
& \mathrm{F}_{\mathrm{CCVD}}=-220,481-0,923143 \times \mathrm{V}+2426,58 \times \mathrm{f}+371,01 \times \mathrm{a}
\end{aligned}
$$

Oluşturulan regresyon denklemlerinin güvenirlik oranları $\left(\mathrm{R}^{2}\right)$ PVD kaplamalı takımlar için \%99,13 ve CVD kaplamalı takımlar için \%98,89 olarak bulunmuştur. Elde edilen güvenirlik oranları 1'e yakın değerler olup, modellerin esas kesme kuvveti değerinin tahmininde kullanılabileceğini ifade etmektedir. PVD kaplamalı takımlarda esas kesme kuvveti oluşumuna \%60,37 kesme derinliği, \%35,86 ilerleme oranı ve \%2,89 kesme hızı etkirken, CVD kaplamalı takımlarda \%57,89 kesme derinliği, \%37,87 ilerleme oranı ve \%3,14 kesme hızı etkimektedir. Her iki kaplama türünde de kesme hızının esas kesme kuvveti oluşumuna etkisi düşüktür. Denklem 3.1 ve Denklem 3.2'de belirtilen denklemler yardımıyla oluşturulan esas kesme kuvvetleri için elde edilen grafikler şekillerde gösterilmiştir.

Şekil 5, Şekil 6, Şekil 7 ve Şekil 8 incelendiğinde, her iki kaplama türünde artan kesme hızı ile esas kesme kuvveti değerlerinde düşüş görülmektedir. Artan kesme derinliklerinde ve ilerleme hızlarında ise esas kesme kuvveti değerleri artmaktadır. 
Nevşehir Bilim ve Teknoloji Dergisi (2019), 8(IMSMATEC Özel Sayı) 1-11

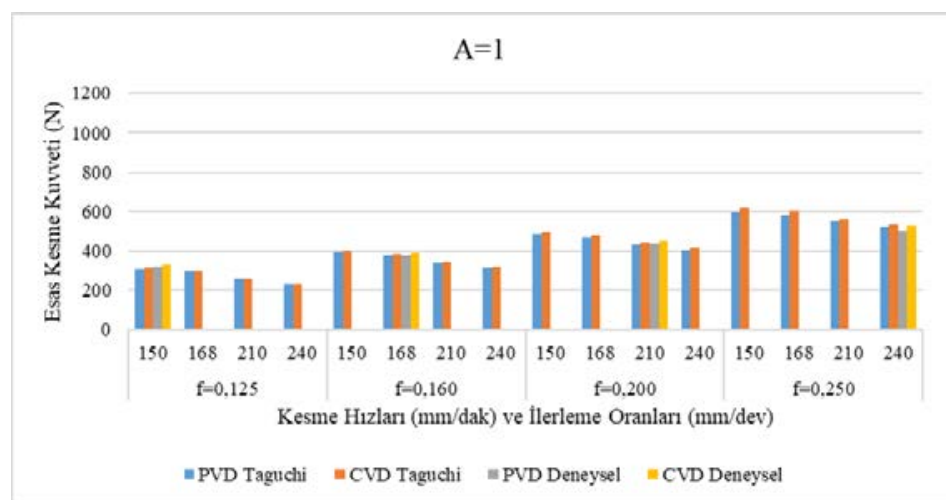

Şekil 5. $1 \mathrm{~mm}$ kesme derinliğinde elde edilen esas kesme kuvvetleri

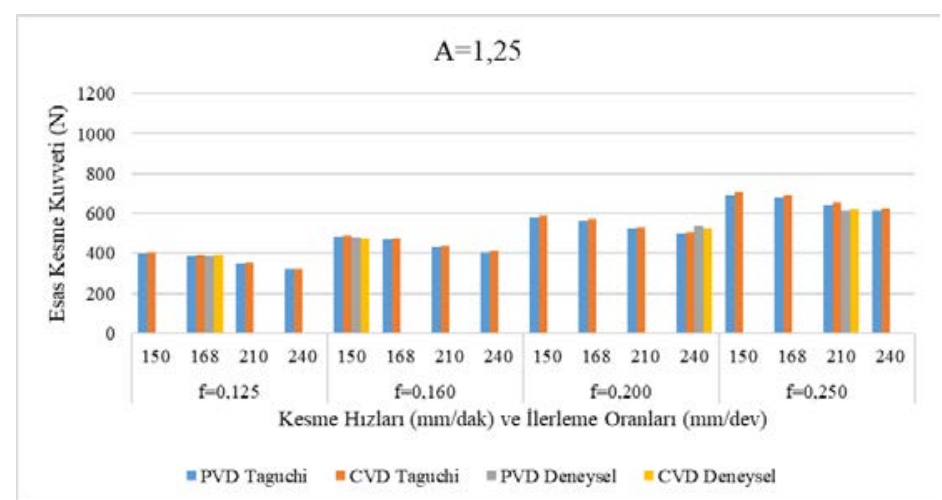

Şekil 6. $1.25 \mathrm{~mm}$ kesme derinliğinde elde edilen esas kesme kuvvetleri

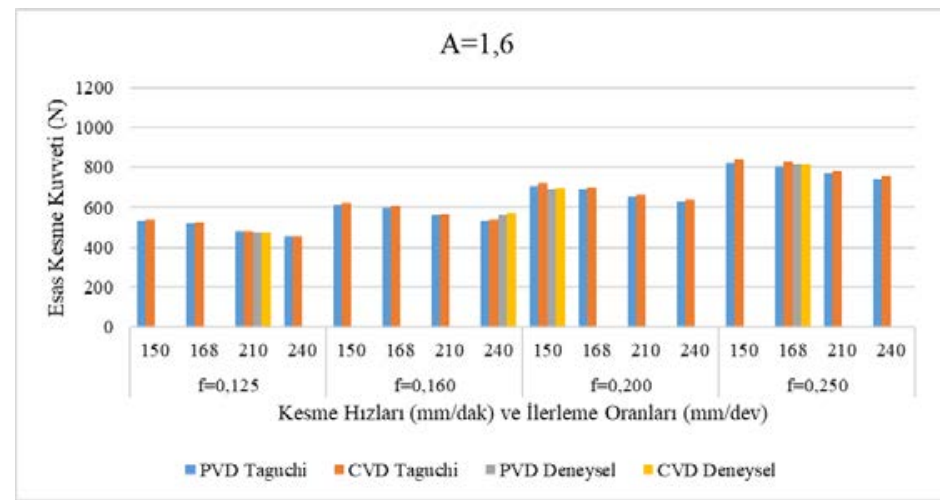

Şekil 7. $1.6 \mathrm{~mm}$ kesme derinliğinde elde edilen esas kesme kuvvetleri

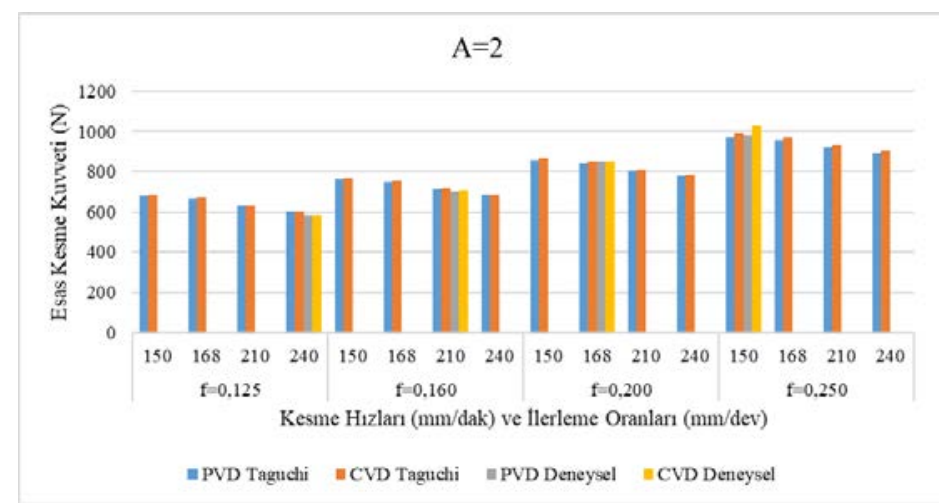

Şekil 8. 2 mm kesme derinliğinde elde edilen esas kesme kuvvetleri 
Yapılan analizler ile elde edilen sinyal gürültü $(\mathrm{S} / \mathrm{N})$ grafikleri Şekil 9 ve Şekil 10'da gösterilmiştir. Oluşturulan sinyal gürültü $(\mathrm{S} / \mathrm{N})$ grafikleri, en küçük-en iyi prensibine göre hazırlanmıştır. Her iki kaplama türü için $\mathrm{S} / \mathrm{N}$ grafikleri incelendiğinde; esas kesme kuvveti açısından optimum kesme parametreleri $240 \mathrm{~m} /$ dak kesme hızı, 0,125 $\mathrm{mm} / \mathrm{dev}$ ilerleme oranı ve $1 \mathrm{~mm}$ kesme derinliğidir.

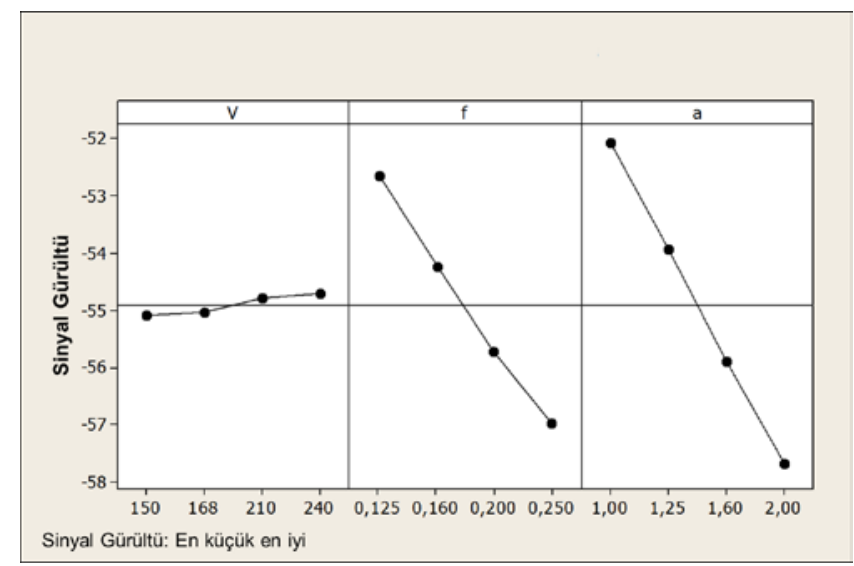

Şekil 9. PVD kaplamalı takımlar için esas kesme kuvveti açısından sinyal gürülttü grafiği

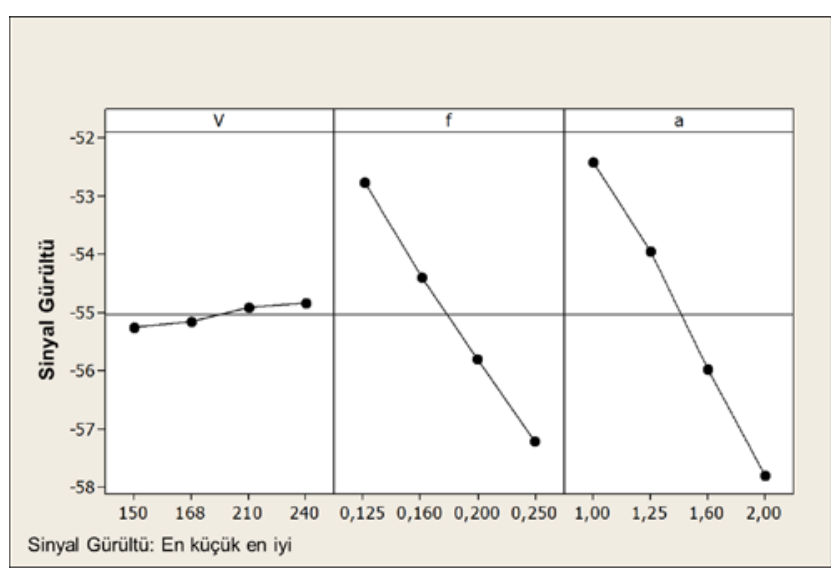

Şekil 10. CVD kaplamalı takımlar için esas kesme kuvveti açısından sinyal gürültü grafiği

\section{2. İlerleme Kuvvetinin Değerlendirilmesi}

Şekil 11 ve Şekil 12 incelendiğinde, PVD ve CVD kaplamalı takımlar için ilerleme kuvveti açısından en etkin parametrenin kesme derinliği olduğu belirlenmiştir. PVD ve CVD kaplamalı takımlar için yapılan varyans analizleri sonucunda elde edilen bu grafiklerin 1şı̆̆gnda ilerleme kuvveti için regresyon denklemleri oluşturulmuştur (Denklem 3.3 ve Denklem 3.4).

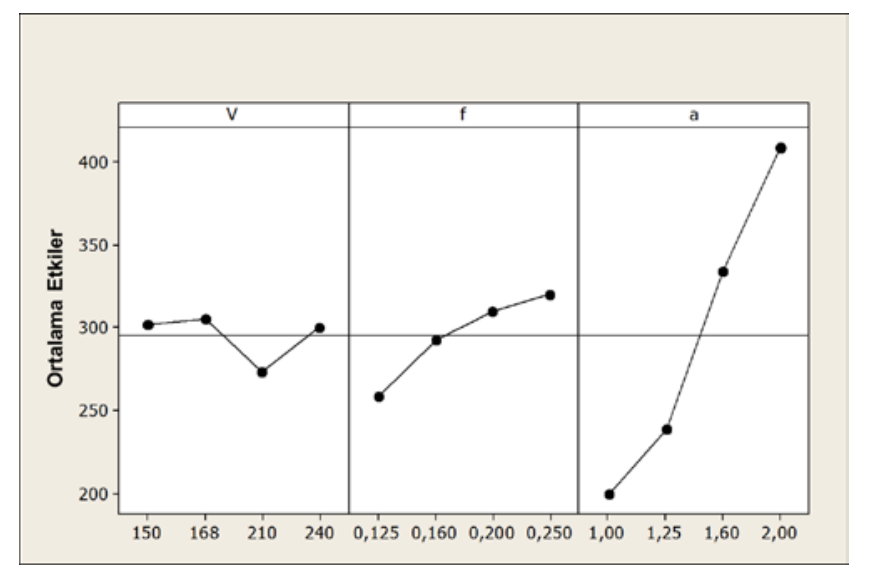

Şekil 11. PVD kaplamalı takımlar için ilerleme kuvveti açısından ortalama etkiler 


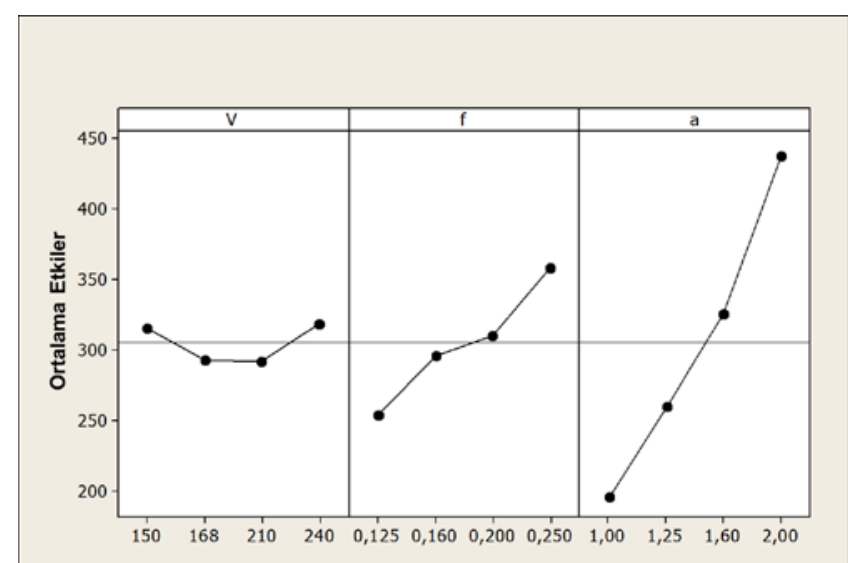

Şekil 12. CVD kaplamalı takımlar için ilerleme kuvveti açısından ortalama etkiler

$$
\begin{aligned}
& \mathrm{F}_{\text {fPVD }}=-80,3515-0,137301 \times \mathrm{V}+473,061 \times \mathrm{f}+215,52 \times \mathrm{a} \\
& \mathrm{F}_{\mathrm{fCVD}}=-194.124-0.0521226 \times \mathrm{V}+783.25 \times \mathrm{f}+235.972 \times \mathrm{a}
\end{aligned}
$$

Oluşturulan regresyon denklemlerinin güvenirlik oranları $\left(\mathrm{R}^{2}\right)$ PVD kaplamalı takımlar için \%93,99 ve CVD kaplamalı takımlar için \%95,1 olarak bulunmuştur. Elde edilen güvenirlik oranları 1'e yakın değerler olup, modellerin esas kesme kuvveti değerinin tahmininde kullanılabileceğini ifade etmektedir. PVD kaplamalı takımlarda \%87,25 kesme derinliğinin, \%6,43 ilerleme oranının ve \%0,31 kesme hızının ilerleme kuvvetinin oluşumunda rol oynadığı görülürken, CVD kaplamalı takımlarda bu oranlar \%81,36 kesme derinliği, \%13,71 ilerleme oranı ve \%0,03 kesme hızıdır. Her iki kaplama türü için de kesme hızının ilerleme kuvveti oluşumu üzerindeki etkisinin çok az olduğu görülmektedir. Denklem 3.3 ve Denklem 3.4'de belirtilen denklemler yardımıyla oluşturulan ilerleme kuvvetleri için elde edilen grafikler şekillerde gösterilmiştir.

Şekil 13, Şekil 14, Şekil 15 ve Şekil 16 incelendiğinde, PVD kaplamalı takımlarda artan kesme hızı ile ilerleme kuvveti değerlerinde düşüş görülmektedir. Ancak CVD kaplamalı takımlarda artan kesme hızlarında ise artış görülmektedir. Her iki kaplama türünde de kesme derinliği ve ilerleme hızı artışı ile ilerleme kuvveti değerleri artmaktadır.

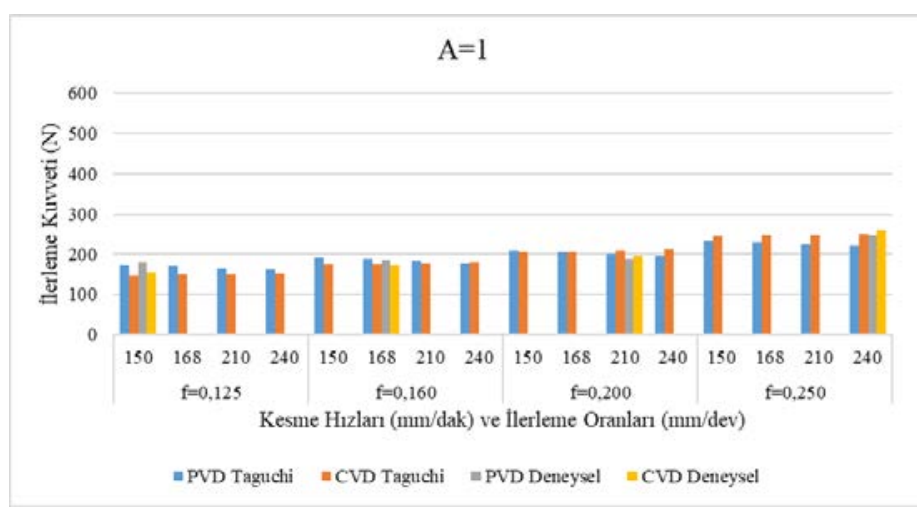

Şekil 13. $1 \mathrm{~mm}$ kesme derinliğinde elde edilen ilerleme kuvvetleri 
Nevşehir Bilim ve Teknoloji Dergisi (2019), 8(IMSMATEC Özel Sayı) 1-11

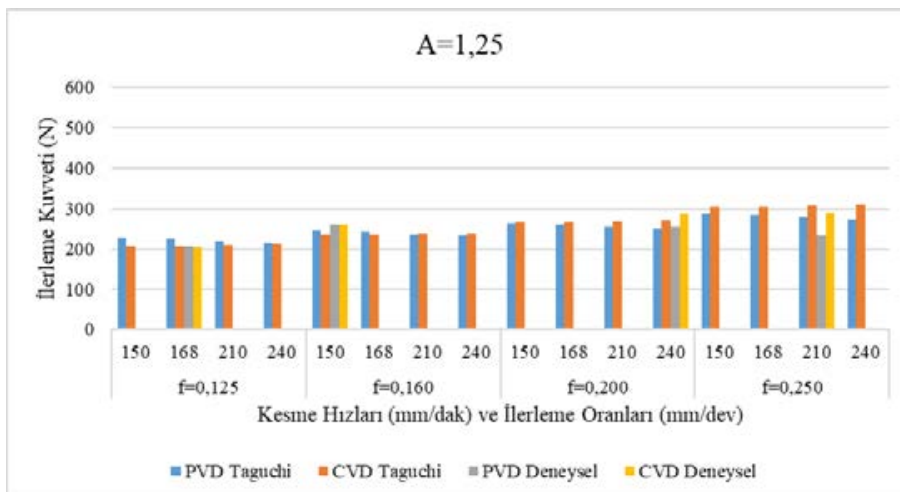

Şekil 14. $1.25 \mathrm{~mm}$ kesme derinliğinde elde edilen ilerleme kuvvetleri

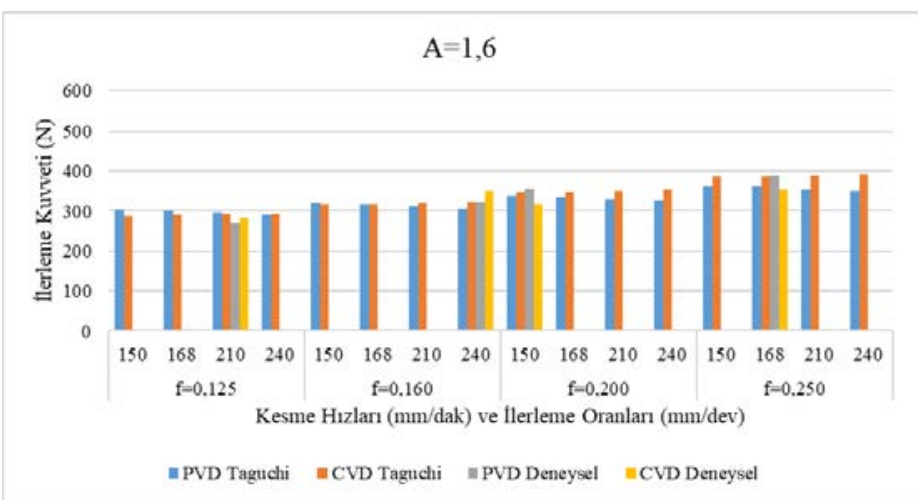

Şekil 15. $1.6 \mathrm{~mm}$ kesme derinliğinde elde edilen ilerleme kuvvetleri

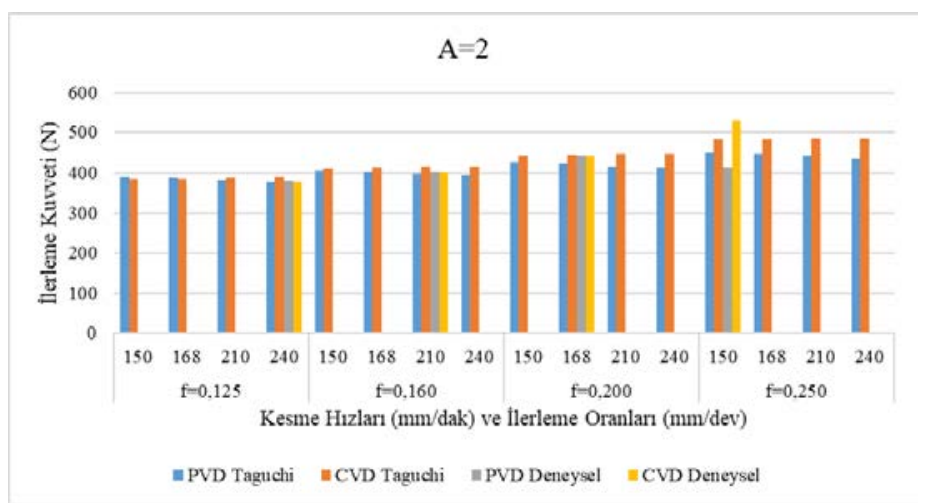

Şekil 16. 2 mm kesme derinliğinde elde edilen ilerleme kuvvetleri

Yapılan analizler ile elde edilen sinyal gürültü $(\mathrm{S} / \mathrm{N})$ grafikleri Şekil 17 ve Şekil 18'de gösterilmiştir. Oluşturulan $\mathrm{S} / \mathrm{N}$ grafikleri en küçük-en iyi prensibine göre hazırlanmıştır. PVD kaplamalı takımlar için S/N grafiği incelendiğinde ilerleme kuvveti açısından optimum kesme parametreleri $210 \mathrm{~m} / \mathrm{dak}$ kesme hızı, 0,125 mm/dev ilerleme oranı ve $1 \mathrm{~mm}$ kesme derinliğidir. Benzer şekilde CVD kaplamalı takımlar için oluşturulan $\mathrm{S} / \mathrm{N}$ grafiği incelendiğinde, ilerleme kuvveti açısından optimum kesme parametreleri $168 \mathrm{~m} / \mathrm{dak}$ kesme hızı, 0,125 mm/dev ilerleme oranı ve $1 \mathrm{~mm}$ kesme derinliği olduğu görülmektedir. 


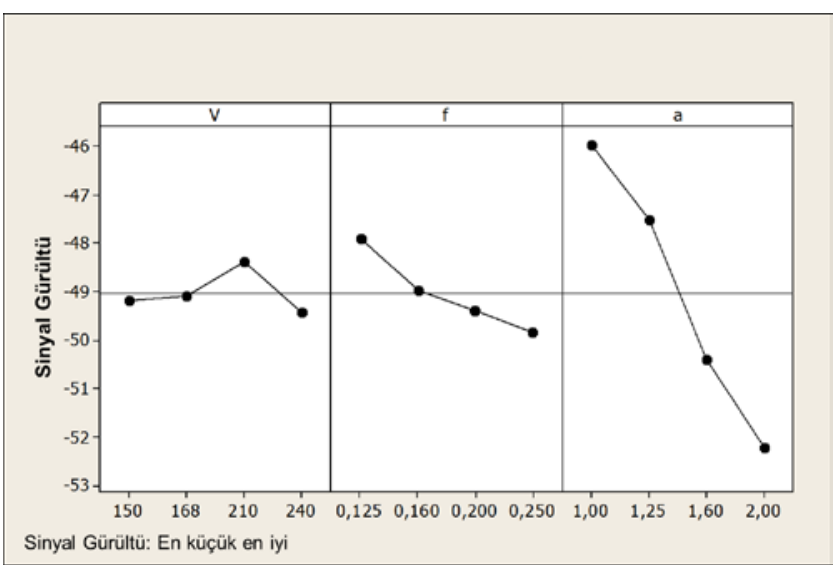

Şekil 17. PVD kaplamalı takımlar için ilerleme kuvveti açısından sinyal gürültü grafiği

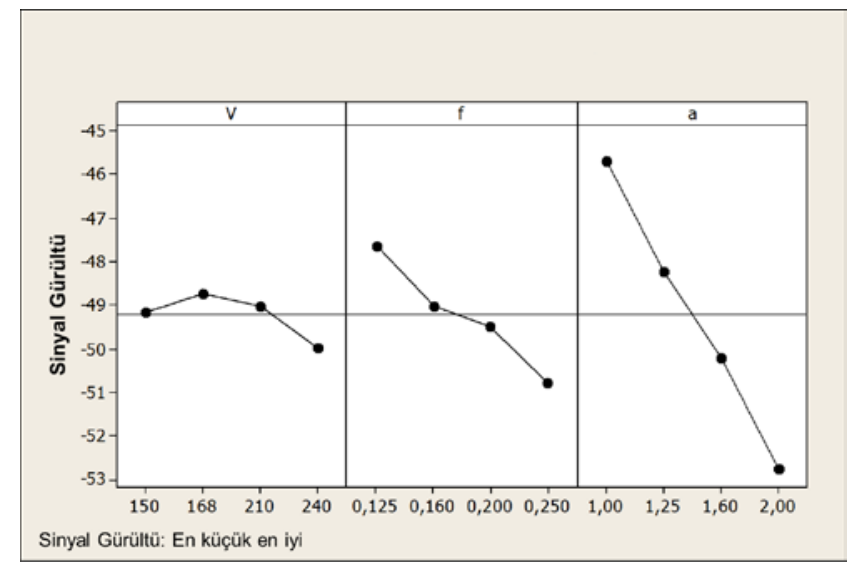

Şekil 18. CVD kaplamalı takımlar için ilerleme kuvveti açısından sinyal gürültü grafiği

\section{Tartışma ve Sonuç}

Yapılan çalışma sonucunda 17-4 PH çeliğinin tornalanmasında, değişen kesme parametreleri ve farklı kaplama türlerinin işlenebilirliğe olan etkisi incelenmiş, optimum kesme parametreleri başarıyla belirlenmiştir. Yapılan çalışma ile elde edilen veriler ışığında, PVD kaplamalı takımlarda kesme hızının artmasıyla esas kesme ve ilerleme kuvvetlerinde düşüş görülmektedir. CVD kaplamalı takımlarda kesme hızının artmasıyla esas kesme kuvveti azalırken, ilerleme kuvveti artmaktadır. İlerleme kuvvetinde gözlenen artışın yüksek kesme hızlarında takım aşınmasının artışına bağlı olarak kaplamanın kalkmasıyla takım serbest yüzeyindeki sürtünme koşullarının değişimi olduğu literatürde karşılaşılmış bir bulgudur [13 ve 19]. Esas kesme kuvvetinin her iki takımda azalması, artan kesme hızının sıcaklığ1 arttırmasına, takım talaş yüzey alanının ve ikinci deformasyon bölgesi olan akma bölgesindeki kayma dayanımının azalmasına, ayrıca sıcaklık artışının talaş akma bölgesi oluşturarak talaş akışını kolaylaştırmasına atfedilmiş̧ir [6]. Her iki kaplama türü için esas kesme ve ilerleme kuvvetleri oluşumunda en etkin parametre kesme derinliği, bunu takiben ilerleme oranıdır. Tüm sonuçların güvenirlik oranı \%90'ın üzerindedir. Kesme hızının artışı ile her iki kaplama türünde de esas kesme kuvveti değerlerinde \%8,05 ile \%25,24 arasında azalma görülmüştür. Ancak PVD kaplamalı takımlarda artan kesme hızı ile ilerleme kuvveti değerlerinde \%0,97 ile \%3,18 arasında azalma, CVD kaplamalı takımlarda ise \%2,78 ile \%7,11 arasında artış olduğu belirlenmiştir. Her iki kaplama türünde esas kesme kuvveti açısından optimum kesme parametreleri $240 \mathrm{~m} /$ dak kesme hızı, $0,125 \mathrm{~mm} / \mathrm{dev}$ ilerleme oranı ve $1 \mathrm{~mm}$ kesme derinliğidir. İlerleme kuvveti açısından optimum kesme parametreleri PVD kaplamalı takımlarda $210 \mathrm{~m} /$ dak kesme hızı, $0,125 \mathrm{~mm} / \mathrm{dev}$ ilerleme oranı ve $1 \mathrm{~mm}$ kesme derinliği, CVD kaplamalı takımlarda ise $168 \mathrm{~m} /$ dak kesme hızı, $0,125 \mathrm{~mm} / \mathrm{dev}$ ilerleme oranı ve $1 \mathrm{~mm}$ kesme derinliği olduğu görülmektedir.

Sonuç olarak 17-4 PH çeliğinin tornalanmasında, PVD kaplamalı takımların kullanımı ile CVD kaplamalı takımlara benzer sonuçlar elde edilmektedir. CVD kaplamalı takımların paslanmaz çeliklerin işlenmesinde en çok kullanılan kaplama türü olmasına karşın, PVD kaplamalı takımların kullanımının da avantajlı olabileceği görülmektedir. 


\section{Kaynaklar}

[1] Trent E. M., Wright P. K., “Metal cutting” First Edition, Butterworths Press, London, 2000.

[2] Shaw M. C., "Metal cutting principles” Third Edition, Oxford University Press, Oxford, 2005.

[3] DeGarmo E. P., Black J. T., Kohser R. A., "Materials and processes in manufacturing” Prentice-Hall, New Jersey, 214-652, 1997.

[4] Berger M., "Development and tribological characterisation of magnetron sputtered $\mathrm{TiB} 2$ and $\mathrm{Cr} / \mathrm{CrN}$ coatings” Uppsala University, Department of Materials and Science, Ph D. Thesis, 7-31, Sweden, 2001.

[5] Uzun G., Yağmur S., Korkut İ., Şeker U., "Hastelloy X süper alaşımının tornalanmasında kriyojenik işlem uygulanan PVD ve CVD kaplamalı takımların performansının incelenmesi” Gazi University Journal of Science Part C, 5(2), 231-239, 2017.

[6] Gürbüz H., Kafkas F., Şeker U., "Kesici takıma farklı yöntemle uygulanmış kaplamaların kesme kuvvetleri ve yüzey pürüzlülüğüne etkisinin deneysel olarak araştırılması” 6th International Advanced Technologies Symposium (IATS’11) May 16-18, 27-32, Elazı̆̆ 2011.

[7] Çelik E., Kıvak T., "17-4 PH paslanmaz çeliğin tornalanmasında minimum miktarda yağlamanın yüzey pürüzlülüğü üzerindeki etkileri” 7th International Symposium on Machining November 3-5, 214-221, İstanbul, 2016.

[8] Gholipour A., Shamanian M., Ashrafizadeh F., "Microstructure and wear behavior of stellite 6 cladding on 17-4 PH stainless steel” Journal of Alloys and Compounds, 509(14), 4905-4909, 2011.

[9] Wen P., Cai Z., Feng Z., Wang G., "Microstructure and mechanical properties of hot wire laser clad layers for repairing precipitation hardening martensitic stainless steel” Optics and Laser Technology, 75, 207-213, 2015.

[10] Singh R., “Stainless steels,” Applied Welding Engineering, First Edition, Butterworth-Heinemann, 65-73, Oxford, 2012.

[11] Mohanty A., Gangopadhyay S., Thakur A., “On applicability of multilayer coated tool in dry machining of aerospace grade stainless steel” Materials and Manufacturing Processes, 31(7), 869-879, 2016.

[12] Çiftçi İ., Kasap M., Şeker U., “Östenitik paslanmaz çeliklerin işlenebilirlik parametrelerinin belirlenmesi üzerine yapılmış deneysel çalışmalar” Z.K.Ü. Karabük Teknik Eğitim Fakültesi Teknoloji Dergisi, 3-4, 130-141, 1999.

[13] Sivaiah P., Chakradhar D., "Comparative evaluations of machining performance during turning of 17-4 PH stainless steel under cryogenic and wet machining conditions” Machining Science and Technology, 22(1), 147-162, 2018.

[14] Çetin Ş., Kıvak T., "Optimization of the machining parameters for the turning of 15-5 PH stainless steels using the taguchi method” Materials and Technology, 51(1), 133-140, 2017.

[15] Kivak T., Uzun G., Ekici E., "An experimental and statistical evaluation of the cutting parameters on the machinability of Hadfield steel” Gazi University Journal of Science, 29(1), 9-17, 2016.

[16] Popovici T. D., Grigorescu M., “The dependence of cutting force upon 17-4 PH machining parameters 2 problem formulations 3 problem solutions” Advances in Production, Automation and Transportation Systems June 1-3, 125-128, 2013.

[17] Ay M., Kalyon A., "CNC torna tezgahında 17-4 PH paslanmaz çeliğin işleme parametrelerinin deneysel olarak belirlenmesi” 6th International Advanced Technologies Symposium (IATS’11), May 16-18, 197-201, Elazı̆̆ 2011.

[18] Fernández-Abia A. I., Barreiro J., Fernández-Larrinoa J., López De Lacalle L. N., Fernández-Valdivielso A., Pereira O. M., "Behaviour of PVD coatings in the turning of austenitic stainless steels" Procedia Engineering, 63, 133-141, 2013.

[19] Chinchanikar, S., Choudhury, S. K., "Investigations on machinability aspects of hardened AISI 4340 steel at different levels of hardness using coated carbide tools” International Journal of Refractory Metals and Hard Materials, 38, 124-133, 2013. 


\section{Extended Abstract}

\section{Introduction}

Turning operation is one the most frequently used manufacturing processes in order to shape the materials. It is an obligatory to evaluate some criteria during this operation. One of these criteria is machinability. It is stated in the literature that machinability is not only related to material properties, but also the type of the manufacturing process and machining parameters. Evaluating the cutting forces is a well-known method for criticizing the machinability of the material.

A quite among of the shaping operations are performed with coated cutting tools. Physical vapor deposition (PVD) and chemical vapor deposition (CVD) are the most preferred methods for cutting tool coatings. PVD and CVD coated cutting tools meet the expectations such as wear resistance, chemical stability, fracture toughness. PVD and CVD coated cutting tools are used in many cases on hard-to-machine materials.

Precipitation hardened (PH) stainless steels have many usage areas owing to its high corrosion resistance, high strength and high hardness degree. Especially 17-4 PH is a very riveting material among the PH stainless steels. This material is used in petroleum, gas and aviation industries.

Even this material offers a more economical solution instead of titanium alloys in the same usage areas, 17-4 PH stainless steel is stated as a hard-to-machine material in the literature because of its high ductility, low thermal conduction, work hardening and built-up-edge (BUE) tendency.

In this study, the determination of optimum cutting parameters was aimed with Taguchi experimental design by evaluating the main cutting force and feed force in turning with PVD and CVD coated cutting tools at different cutting parameters, and the effect of coating type on machinability.

\section{Method}

The experiments were performed with CNC turning machine. Cutting forces were obtained with Kistler 9257B dynamometer connected to a Kistler Type 5019 multichannel charge amplifier and measured with Dynoware Type 2825Ai-2 software. The test specimens were $80 \times 500 \mathrm{~mm}$ sized rounded bars, which were at $37 \mathrm{HRC}$ hardness level and H1025 heat-treated. PVD and CVD coated cutting tools were used in the experiments. The cutting tools had exactly the same geometry, coded as SNMG 120408-MM by Sandvik Coromant. Taguchi $\mathrm{L}_{16}$ experimental design was used as cutting parameters with three different factors and four different levels. ANOVA and regression analysis was performed in order to evaluate the effectiveness of the cutting parameters, also determining the optimum cutting parameters.

\section{Results and Discussion}

In this study, the optimum cutting parameters for 17-4 PH material was successfully determined for each coating type in terms of main cutting force and feed force. All results were displayed with graphical figures. Familiar results were obtained with PVD and CVD coated cutting tools. Cutting depth is the most effective parameter for main cutting force and feed force occurrences, followed by feed rate. Cutting speed increasement reduces the main cutting force for both coating types. The increase of cutting speed reduces the feed force for PVD coated cutting tools. It is stated in the literature that the increase of feed force caused of the wear increasement at high cutting speeds, thus the coating layer will be lost and friction conditions will be changed at the clearance face of the cutting tool. However, the increase of cutting speed increases the feed force for CVD coated cutting tools. All confidence ratios $\left(\mathrm{R}^{2}\right)$ were obtained over $90 \%$. It can be said that even CVD coated cutting tools are the most preferred ones in machining stainless steels, PVD coated cutting tools may be more favorable than CVD coated cutting tools. 